J. Percy: Astronomers should not wait to be invited to serve on curriculum advisory boards and committees. They should invite themselves to become involved as soon as they know that such boards and committees exist.

J.E. Bishop: My reason for bringing this historical topic to the attention of the group is hope that awareness of it might motivate many to do exactly what Drs. Osborn and Percy recommend. Astronomers need to be better "cheerleaders" for their subject. I suggest these ways of becoming involved with pre-college science education: 1) offer to participate in programs or meetings for school administrators; 2) write enthusiastic articles about the nature and importance of science (with astronomy) for journals of school administrators, school boards, and educational regulation agencies; and 3) generally befriend and offer advisory support to officials in positions to make key educational decisions.

J.M. Pasachoff: In American colleges and universities, at least, physicists often think that they can properly teach astronomy, and astronomy sometimes is forced to take a junior role in joint departments of physics and astronomy. Physicists, however, usually lack the breadth of astronomical experience to be able to tie together celestial topics from an astronomical point of view. Further, when astronomers lose their independence, their access to university administration and to funding is diminished. I feel that the smaller the department, the more important it is for the astronomers to be independent. After all, a relatively large group of astronomers can defend themselves. We astronomers should be emphasizing that astronomy is a separate science from physics, and that astronomy departments should be independent.

\title{
SCIENCE TEACHING THROUGH ITS ASTRONOMICAL ROOTS
}

Philip M. Sadler and William M. Luzader, Project STAR, Harvard-Smithsonian Center for Astrophysics, 60 Garden Street, Cambridge, Massachusetts 02138 U.S.A.

\section{Introduction}

Project STAR (Science Teaching through its Astronomical Roots) emerged from growing concern about the decreasing enrollment in science classes, and lack of understanding of science and math concepts ${ }^{1}$ (Figure 1). Using astronomy as a focus, Project STAR is trying not simply to increase the enrollment in high school science courses, but also to improve the students' understanding of science and its role in making sense of the world. 


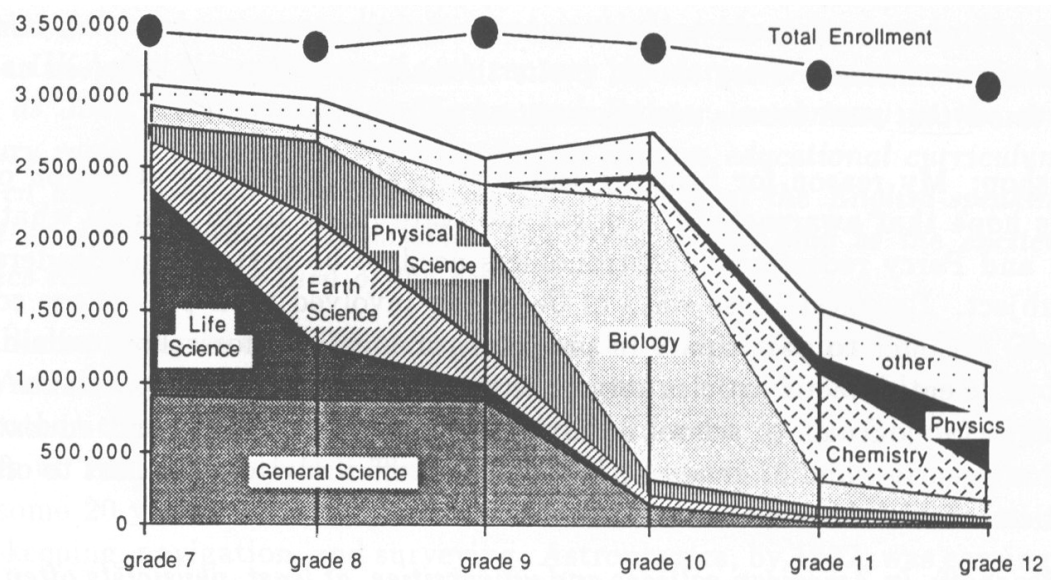

Fig. 1. Science enrollments in U.S. schools 1981-82 (from "How Many are Enrolled in Science?" The Science Teacher, NSTA, December 1984.

The educational approach of Project STAR is based on three principles:

- Mastery of a few ideas is more important for students than cursory exposure to many concepts.

- Students learn best through hands-on activities.

- Students enter the classroom with certain preconceptions, or "naive theories," about how physical systems work, without a sense of whether their understandings are accurate (often they are not).

To develop a curriculum around these principles, a team of scientists, high school teachers, and support professionals was assembled at the Harvard-Smithsonian Center for Astrophysics (CfA) in Cambridge, Massachusetts, and has been active since August 1985.

\section{Goals of the Project}

In the initial stage of the project, we have sought to develop three units of a high school course that would use astronomy as a basis for teaching principles of science and mathematics. Each unit involves approximately three weeks of classroom time. The materials developed and being tested are:

1. student activities and teacher guide,

2. computer software, and

3. video tapes and films.

\section{Background}

Before beginning the curriculum development process, we spent time looking 
into areas that could have a major impact on the effectiveness of our work. Much as a business extensively investigates a new product area, we explored opportunities to increase the probability of success.

\section{A. Past Successes and Failures}

During the last 30 years, there have been many attempts to produce popular and effective courses, through cooperation between university and public school educators. Some were successful and remain in use, such as BSCS Biology which is used in about 40 per cent of U.S high schools. ${ }^{2}$ Some are out of print and no longer in use. Others, such as PSSC Physics and Harvard Project Physics, were initially successful but have declined in popularity. Some of the activities from these projects are still used as parts of courses.

These curriculum efforts used many different approaches to content, teaching style, laboratory activities, teacher training and dissemination. To benefit from their experiences, we conducted telephone and personal interviews with many of the principal investigators of these curriculum projects. These informal conversations revealed that:

1. Most teacher training concentrated more on the theoretical aspects of the curricula and proved to be ineffective.

2. There was little concern for the complexities of dissemination and marketing of the material.

3. Royalties from developed materials were returned to the NSF instead of to the project, making ongoing project activities, teacher training, and revision difficult.

4. Teachers had little time to assemble "hands on" materials and even less money for the repair and replacement of equipment.

5. The courses were directed at top students, thus neglecting the largest body of students.

6. New curricula were costly to develop.

\section{B. Naive Theories}

Recent educational research has revealed that students learn very little in their science courses. ${ }^{3}$ Cognitive researchers have found that students learn science concepts much more slowly than their teachers believed. High-school science classes race through thousands of new words, symbols, definitions and concepts. Very few of these words, symbols, definitions, and concepts are actually understood by the students; almost none can be applied to new situations.

This research has shown that students have explanations for physical phenomena that are based on their own unique experience and logic. For example, when students and/or adults are asked about the cause of the Earth's seasons, most respond by saying, "The closer we are to the sun, the hotter it is." Very few even 
attempt an answer relating to the tilt of the Earth's axis, the varying length of daylight or the altitude of the sun in the sky, in spite of instruction to the contrary.

"Pre-conceived Knowledge" or "Naive Theories" can become critical barriers to the understanding of physics or any other science. Students' theories are notoriously resistant to change. Most students hold on to these explanations and never fully accept the more powerful scientific concepts. As a result, their intuitions about how things behave in the natural world never change and they cannot apply new concepts to their everyday experience.

Project STAR provides an opportunity to uncover the "naive theories" that students (or even adults) have about basic astronomical concepts. We attempted to develop materials and teaching methods that could effectively challenge these theories and replace them with more powerful, accepted ideas.

\section{The Team}

The Center for Astrophysics is a unique environment. At this one location, there are experts in almost every area of astronomy and astrophysics. Many are involved in state-of-the-art research and have distinguished teaching careers at Harvard. Several are accomplished authors as well. We have enlisted several of these individuals in an ongoing advisory capacity. This Science Panel has met weekly since the beginning of the project to discuss details of the program and to review materials that have been developed.

Local and national astronomy teachers have also been a key resource of Project STAR. Their experience and insights have helped move the project along more rapidly. In monthly meetings, local teachers provide feedback on what concepts students can learn and what materials work in their own classrooms. The teachers from outside Massachusetts keep records of their daily experiences with the students and the materials. These records are then sent to the project staff for evaluation and for incorporation in revised materials. During the $1986-87$ academic year, nine Massachusetts teachers helped develop and then used our materials. During the 1987-88 academic year, they were joined by 17 additional teachers from around the U.S. in revising and trial teaching revised materials. Approximately 700 students used these new materials.

Project STAR has been fortunate in attracting teachers to take sabbaticals as project associates. In this way we have managed to have those with current classroom experience developing materials, leading workshops and working with CfA scientists.

\section{Projects}

\section{A. Astronomy Education Survey}

Before beginning our curriculum development, we wanted to find out how astronomy was being taught in high schools around the country. How much information existed regarding secondary level astronomy education? Where was it being 
taught? Who was teaching it?

Reference to astronomy in the nation's schools can be found in the $1977 \mathrm{Na}$ tional Survey of Science, Mathematics and Social Studies Education. In schools with grades 10-12, astronomy was offered as a course in 6 per cent of the schools to 46,375 students. The number of schools with astronomy courses, 1,318 , could also be interpreted as the minimum number of teachers who teach astronomy, since at least one teacher is needed to teach one course in a school.

An initial telephone survey of the school systems within the Greater Boston area (enclosed by Route 128, a circular highway about $20 \mathrm{~km}$ from downtown), showed that there are 6 high schools out of 54 school systems with separate astronomy courses. Extrapolating this ratio to the nation, the 16,000 school systems may have as many as 1800 astronomy teachers. While our sample was too small and non-random for any such conclusion to be reliable, we do infer that there are about 1,500 teachers and about 50,000 students involved in astronomy.

\section{i) Initial Census - May 1986}

To determine more accurately the extent to which astronomy is being taught in the nation's schools, we secured the names and addresses of 11,100 science department heads from the National Science Teachers Association and mailed each one a short questionnaire. The questionnaire included a very brief description of the project's goals and six questions related to the teaching of astronomy. These cards were mailed postpaid on May 15, 1986. Within four weeks, 23 per cent of the cards were returned and we learned that 15 per cent of the responding schools offer separate astronomy courses. The results have helped to develop a picture of the role that astronomy plays in secondary schools.

Fifty-six per cent of the responding high schools offer astronomy to their students as part of Earth Science, Earth and Space Science, or Physics. Over 15 per cent offer a separate astronomy course for one or two semesters. The large majority of Science Department Heads (76 per cent) would like more astronomy to be taught in their schools.

The national significance of these figures should not be underestimated. The number of qualified physics teachers in U.S. high schools has been dwindling for the last ten years. The best estimate from the American Association of Physics Teachers is that only about 8,000 remain. ${ }^{4}$ By supporting and increasing the number of astronomy teachers in the nation's schools, it might be possible to attract more students to physical science in eleventh or twelfth grade. At present, only about 35 per cent of high school students take a physical science course (chemistry or physics) before graduation. ${ }^{5}$ One approach to get more students into science classes is to increase their options.

\section{ii) Teacher Survey - June 1986}

One of the key questions on the census card was: "If an astronomy course is offered, who is the teacher?" Among the 2400 respondents, our census identified 
408 teachers who taught courses of one semester or longer. The Project then mailed to these teachers a more detailed eight-page questionnaire.

Of the questionnaires sent to astronomy teachers, 62 per cent responded before school closed. We believe we gained thereby a strong sense of the attitude and needs of astronomy teachers. We estimate that 800 to 1200 more astronomy teachers remain to be identified.

The follow-up survey of the 408 identified teachers uncovered several remarkable facts. Most of these teachers are aware of the lack of curriculum materials and of any high school level textbooks. They have adapted by using college-level texts and developing their own courses and curricula. Today's astronomy teachers are a dedicated group of science educators. Most of them teach other science courses, and most of them have little or no interaction with other astronomy teachers elsewhere. Moreover, most of the astronomy courses are taught by the teacher who developed the course, and when that person no longer teaches it, the course is often discontinued. The most striking response to our survey was one of unabashed enthusiasm. "Finally," one of the teachers said, "we will have a forum."

These teachers had varied backgrounds. One might think that all astronomy teachers would also teach physics. Although a plurality did, all the other sciences were represented as well. Even some mathematics teachers are teaching astronomy (Figure 2).

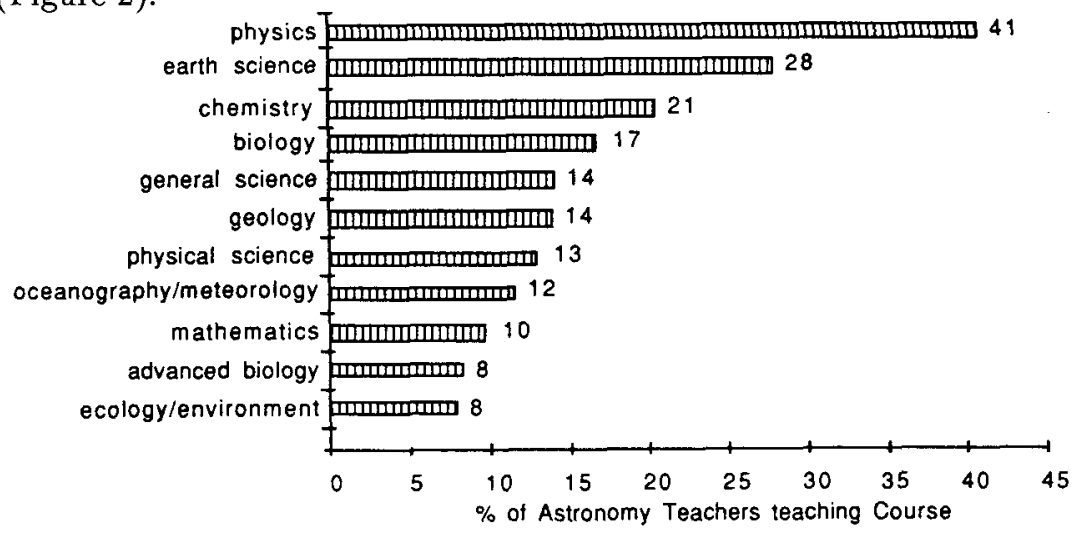

\section{Fig. 2. Other Courses Taught by Astronomy Teachers}

Most of these teachers ( 77 per cent) consider astronomy their hobby and many own telescopes and subscribe to popular hobbyist magazines. Thirty-six per cent of the astronomy teachers are members of astronomy societies or organizations. Thus, astronomy is not only a course they teach but also a lifelong avocation. By comparison, few high school science teachers consider themselves amateur physicists or amateur chemists. Many teachers have enough confidence in their knowledge/mastery of the subject matter to develop a unique astronomy course. Eighty per cent have written their own curriculum materials and laboratory activities. Only 14 per cent use a commercial text. As far as we know, no other subject generates this sort of 
grassroots interest. These facts demonstrate the interest and dedication of astronomy teachers.

Slightly more than half ( 57 per cent) of the teachers teach one astronomy class; the remainder teach from two to seven classes. Most courses are one semester long, but several schools offer full year courses. The average class size is 25 pupils.

The teachers identified four areas in which they were most dissatisfied. They want:

- Higher quality student and classroom activities and computer programs.

- A student workbook in astronomy (the need most often cited).

- Summer workshops in astronomy.

- Astronomy education newsletter or association.

In individual interviews with 25 astronomy teachers, we found that almost all thought they were the only teachers offering astronomy courses in their region of the country. Even teachers who taught in adjacent communities rarely knew of each other's existence. Their strong desire for a newsletter or association serving their needs reflects this feeling of isolation.

High-school astronomy teachers represent an extraordinarily dedicated group. Our goal has been to help support and expand the astronomy offerings. Moreover, teachers interested in teaching astronomy can be supported by these dedicated teachers. By sponsoring workshops, we are encouraging the teaching of more astronomy courses. Experienced and enthusiastic astronomy teachers are the natural choice for leaders of, and speakers at, these events. Many teachers have requested materials for integrating astronomy activities and topics into courses other than astronomy. These teachers could also help to lead the effort to incorporate more astronomy into earth science, chemistry, physics, and mathematics courses in the nation's schools.

\section{B. Resource Review}

Between 1956 and 1975 , more than $\$ 387,000,000$ was spent by NSF in efforts to produce and disseminate curriculum materials. ${ }^{6}$ It has been very costly to write entirely new material, so we have worked to adapt existing materials whenever possible.

To aid this effort, Project STAR has assembled a resource library of astronomy education materials appropriate to our target audience. It includes teaching materials, articles, media, computer software, texts, and activity lab manuals. Research materials have been gathered, including dissertations, articles, studies, and reports on astronomy education. Teaching support materials have been acquired when practical, including posters, photographs, slide sets, simple models and equipment. Many of these materials were acquired at no cost by requesting them from publishers or individuals. These materials have been an excellent source of ideas. 


\section{Summer Institutes}

\section{i) July 1986}

For STAR's first Summer Institute, a team of consulting teachers, along with the project's scientific and support staff, worked with consultants, authors, educators and workshop leaders for four weeks at the Center for Astrophysics. The goal was to establish a unified approach to the creation of the Project STAR curriculum. This Institute was intended to be the first of a continuing series of summer institutes aimed at further developing teacher competency in astronomy and space science.

The Summer Institute consisted of three integral parts:

1. Lectures and workshops on the latest developments in astronomy to provide the teachers with the opportunity to interact with researchers;

2. Workshops on astronomy education, centered on the materials and resources already developed by the Project STAR group at the Center for Astrophysics; and

3. Working sessions where new astronomy teaching materials were developed by the participants.

The primary goals were to help the participants to become more effective science teachers and to develop them as leaders to expand high school astronomy offerings in their locales. These participating teachers have served not only as resources to STAR but also as resources to their home communities by dispersing the ideas learned in the Summer Institute to fellow teachers in their local systems.

The teachers worked in three teams to draft the three curriculum modules: The Solar System, Stars, and Galaxies. They wrote activities and used overheads and slides to present their results at the last session of the Institute. The Institute was a great success in terms of building a team and establishing direction.

\section{ii) August 1987}

For the 1987 Summer Institute, 18 astronomy teachers from around the country came to the CfA for workshops about naive theories, STAR activities, and lectures on recent research on astronomy and astrophysics. They learned to teach the STAR curriculum materials and advised the staff on revisions. During the 1987-88 academic year, they used these materials in their own classrooms and administered tests to determine the materials' effectiveness. After using the materials they submitted detailed critiques and suggestions based on their experiences.

\section{Computer Applications}

\section{i) Microcomputer-Based Spectrophotometer}

A microcomputer-based spectrophotometer has been developed for Project STAR by the Technical Education Research Center (TERC). It has a broad appeal not only for astronomy classes but for physics and chemistry classes as well. 
This real-time apparatus facilitates a wide range of experiments involving light. Using a linear photodiode array, a prism or grating, and some simple electronics, it generates a color display of the spectrum for many light sources: gas discharge lamps, filament lamps, flourescent tubes, the sky, the sun, filters, and fluorescing materials.

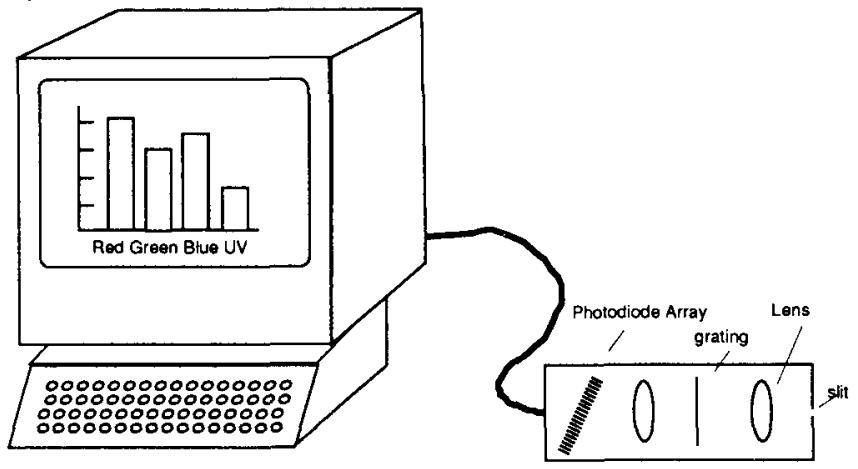

Apple lle Microcomputer

Light Probe

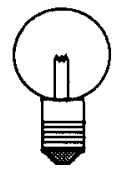

Light Source

Fig. 3. Microcomputer-Based Spectrophotometer

\section{ii) Spreadsheet Astronomy}

We experimented with the use of computer spreadsheets and graphics to teach astronomical concepts. With only a few direct measurements on each of the 500 brightest stars in the sky, various graphs and charts could be produced.

A plot of right ascension vs. declination of these stars will produce an equatorial star chart. This map was used in an activity to determine the structure of the Milky Way Galaxy. This same information is used to produce charts that plot stars from a polar point of view for both the northern and southern hemispheres. These charts are cut, folded and taped together to create a spherical star map. They are used in the construction of the student celestial spheres, referred to the Low-Cost/High-Tech section.

\section{iii) Desktop Publishing}

Project STAR must produce hundreds of documents, involving text, tables and graphics. Previous curriculum projects have employed graphics artists, typists, typesetters and illustrators. Many have used outside services, which are costly and can slow production. Project STAR uses a modern and efficient desktop publishing system, the Macintosh Office with an Apple Laserwriter. This technology saves time and money, streamlines the production process and allows a much larger number of contributors to be involved in the writing process. Our newsletter, STARnews, is produced in-house.

\section{iv) Animation Software}

Microcomputers have tremendous power to simulate systems. Existing soft- 
ware can provide students with many experiences which are impossible or difficult to transmit in a laboratory, planetarium, or classroom. "Planetarium" programs can set up the sky for any season, time or location. Students can make measurements of the positions of stars, planets, the sun or the moon. Microcomputers can simulate gravitational systems from a single rocket in space to many-body problems. Drill and practice software can teach students basic measuring techniques used by astronomers.

For example, gravity simulations of galaxy "collisions" were created by generating individual frames with a Pascal compiler. The frames were then combined using software written to make computer movies. Students will be able to watch these simulations to get an understanding of gravitational interaction on a galactic scale.

\section{v) Models of the Solar System}

Below are frames from two animations showing the motion of Venus. The frames show the Earth-moon-sun system from above and the appearance of Venus with respect to the sun as seen from Earth. Students can compare a heliocentric model (Figure 4a) with a geocentric model (Figure 4b). Students can experience firsthand how observation can be used to test a theory. They can view these two simulations, then make direct observations to determine whether a theory is consistent with the data.
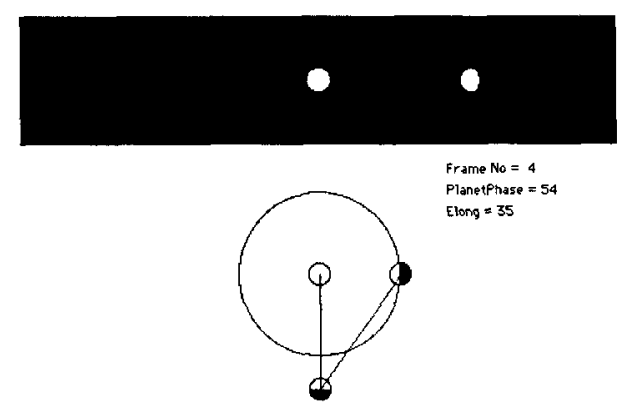
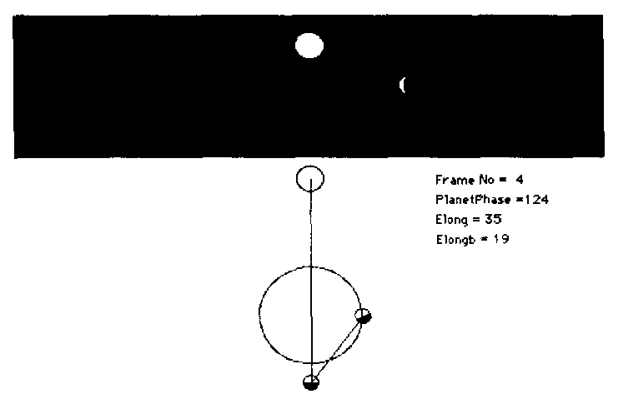

Fig. 4a (left): Heliocentric model of the Earth, Venus, and the sun; Fig. $4 b$ (right): Geocentric model of the Earth, Venus, and the sun.

These simulations run very slowly, even on high performance microcomputers such as the Macintosh. Although they will run much faster on supermicros, and presumably on the next generation of normal microcomputers, interactive capability is not currently possible. Frame generation time is from 10 to 60 seconds. We have converted several simulations to videotape for classroom trials. Other possible simulations include moon phases, the altitude of the sun throughout the year, and the path and speed of comets. 


\section{E. Naive-Theories Film}

Over the last few years, science teaching literature has produced many articles about student misconceptions and naive theories. We are convinced that students' prior beliefs about the world play a major role in the learning of science. Many researchers have found that paying attention to the preconceived ideas of students is a very effective strategy for science teachers. Many teachers, however, are unaware - or at least tend to minimize - the role of these ideas. They often attribute much more understanding to students than they possess, seemingly because students use scientific terms and phrases without really understanding them.

Dr. Matthew Schneps has produced a video entitled "A Private Universe" that demonstrates the powerful role that these preconceived ideas play in learning science. In interviews with college seniors at graduation and with high-school freshman before being taught about the seasons, it was found that both groups have the same misconceptions about the cause of the seasons on the Earth. The high-school students are interviewed again after instruction. The film illustrates the role that model building and discussion play in student learning.

"A Private Universe," which is being distributed by Pyramid Films, has won a Gold Medal at the Houston International Film Festival and a Silver Apple at the National Educational Film and Video Festival in Seattle, Washington. It has been used extensively for teacher workshops during the 1987-88 school year, where it stimulated interesting discussions about the learning and teaching of science.

\section{Curriculum Development}

\section{A. General Outline}

Project STAR has developed a unique set of materials for high school astronomy teachers. Built around the idea that students best learn science by confronting their models of scientific concepts and applying them in both astronomical and terrestrial situations, we have concentrated on the following conceptual areas Orientation in Time and Space, Laws of Nature and Nature of Light. Each conceptual area is discussed from three perspectives: The Solar System, The Stars, and The Galaxies. Each perspective of a conceptual area constituted a single STAR Module (creating nine STAR modules). STAR Modules are materials which can be taught in two to four weeks, and include teacher notes, laboratory supplies and students workbooks.

\section{i) The First Three Modules}

The first set of activities to be prepared related to Orientation in Time and Space. Each activity begins with a prediction in which the students make a commitment to their misconceptions about nature. This prediction is addressed during the activity so the students will discard their misconceptions and accept more powerful concepts. The specific modules developed for this unit were: 
The Solar System: The concepts of measuring distance and size are developed by angular measurement of nearby ob jects and astronomical objects using similar triangles. Students used this information to build scale models of the solar system.

The Stars: This module begins with an exploration of how the intensity of light decreases with distance. Using simple equipment, students measure light in the classroom, then progress to measuring the luminosity of the sun and stars. By performing simple calculations, they then estimate the distance to nearby stars. Using geometric methods developed in The Solar System module, students compare the results of distance measurements made with different methods.

The Galaxies: By classifying various deep-sky objects and plotting these objects on a map of the sky, the students construct a model of our own Galaxy. The sizes of, and distance to, various galaxies are estimated using the methods developed in the first two modules. From reproductions of Palomar and Lick Sky Surveys and photographs from the Harvard Observatory plate stacks, students make calculations and build a model of our local group of galaxies.

\section{ii) Future Modules}

Activities for the other two units, Laws of Nature and the Nature of Light, were outlined by the teachers at the 1987 Summer Institute:

Laws of Nature: orbital motion and gravity, gas laws, nuclear energy;

Nature of Light: spectral analysis, temperature and color of stars, sizes of stars, stellar evolution

The activities for these units will be produced under the proposed extension of the project.

\section{B. Student Journals}

In keeping with the "learning by doing" philosophy of Project STAR, student journals were used as a tool for promoting students' understanding of science concepts. Project STAR consulting teachers used two such techniques: Moonwatch and Sunwatch exercises and Moon Journals. In the Moonwatch and Sunwatch, students draw the surroundings of their observation spot and record the position of the sun or the moon over a period of two weeks to three months. They acquire an intuitive understanding of the paths of the sun and/or the moon before clarifying it intellectually through class discussion. The Moon Journal is a record of daily observations of the moon - not just its position, but other details as well - shape, color, thoughts about past observations, questions, etc.

The more detailed their observations, the better. This exercise stimulates them to think more carefully about the causes and effects of the phenomena they observe. They notice things that they would not have noticed before. They understand more about how things work and they have more questions. 


\section{Low Cost Equipment for Activities}

One of the responses to the teacher questionnaire was the lack of student activities involving observation and prediction. Thus the project designed several inexpensive and versatile pieces of equipment that have been tested in participating schools and at teacher workshops. These activities have become the most popular parts of the curriculum.

\section{i) Celestial Spheres}

Astronomy is a very "spatial" science. However, most students have great difficulty mastering the spatial relationships posed in most textbooks. STAR has developed a very inexpensive $(<50$ cents) celestial sphere that students construct themselves.

The celestial sphere is assembled from two vacuum-formed clear plastic hemispheres on which the students trace the position of the stars from a spherical star map. A reformed metal coat hanger supports a small earth globe inside the hemispheres to form the completed sphere.

As the sphere is built, the students practice constellation identification. After it is built, a pin, representing the sun, is placed at various places along the ecliptic to model the changing position of the setting sun for a period of a few months. It may then be used to predict future positions of the sun and the visibility of certain constellations at various times during the year. A single hemisphere is used to track the daily motion of the sun at different days during two seasons.

\section{ii) Telescope}

An essential part of any introductory astronomy course is an explanation of how a telescope works. For under 50 cents, each student can make a telescope comparable to that which Galileo used to make his first astronomical observations.
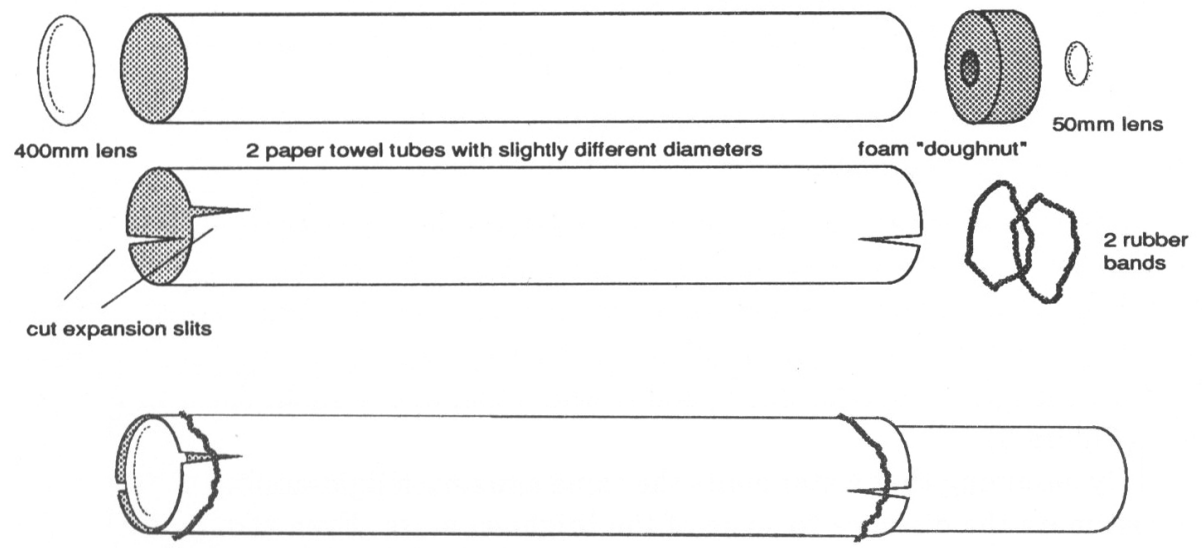

Fig. 5. A simple, inexpensive telescope for an introductory astronomy course. 
The molded plastic lenses and foam insert are inexpensive, while the rest of the materials may be collected in the student's home. Also, by adding a simple reticle, measuring angular sizes becomes a straightforward task. Using this instrument, the student can make quantitative observations of terrestrial objects and the moon's surface.

\section{iii) Luminosity of the Sun}

How bright is the sun? How far away are the stars? The inverse-square law is a fundamental tool in answering these questions. Some interesting and useful activities can be carried out with an easy-to-build device called a null photometer, which was used in the PSSC Physics lab exercises (Figure 6). Using this device, students observe that nine lights are needed to illuminate a surface three times the distance of one light, thus verifying the inverse square law. Given the Earth-sun distance, measuring the photometer-bulb distance, and then using the inverse square law, the students can also determine the power output of the sun by comparing it to a known source such as a 200 -watt light bulb (Figure 7).
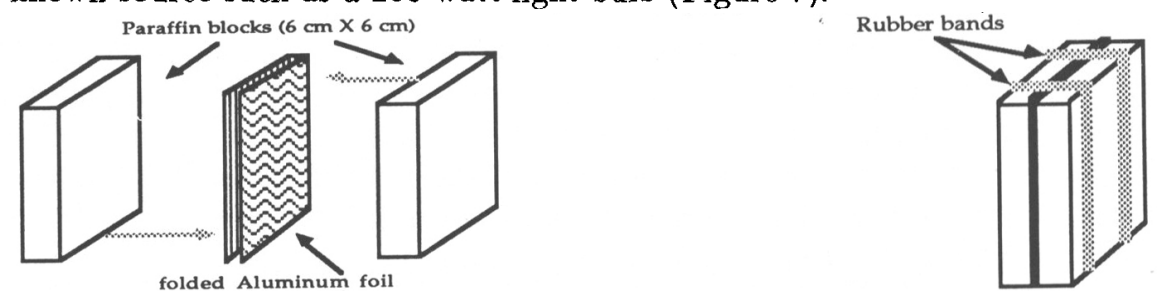

Fig. 6. A null photometer. When the photometer is illuminated equally from both front and back, the aluminum foil "disappears."

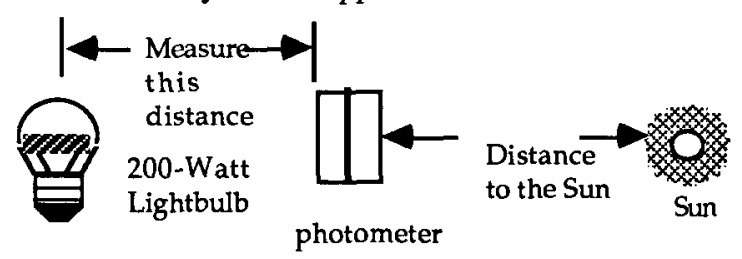

Fig. 7. A simple experiment to measure the power of the sun, using a null photometer.

The inverse-square law is also used to determine the distance to a bright star. For this activity the students build an artificial star from optical fiber. This device, when held at the proper distance, matches the apparent brightness of some star in the sky. They use an ordinary flashlight (with two D-cell batteries), a piece of plastic thread (a length of optical fiber), some clear tape, and a small sheet of aluminum foil) (Figure 8).

By assuming that a star emits the same amount of light as the sun, the student can estimate the distance to some of the brightest stars. Even though the numbers were not exact, this approach gave results to the correct order of magnitude. 


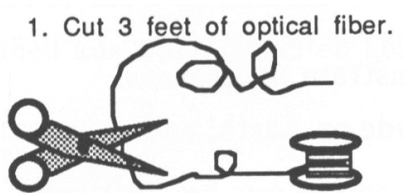

3. Tape fiber across face of flashlight.

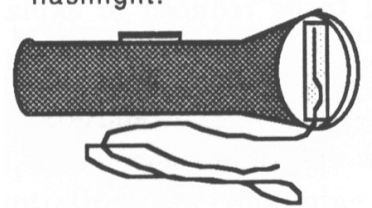

2. Cut 2 inches of transparent tape.

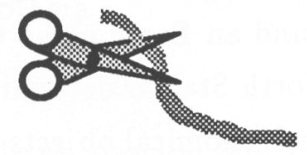

4. Cover end of flashlight with aluminum foil so that no light escapes.

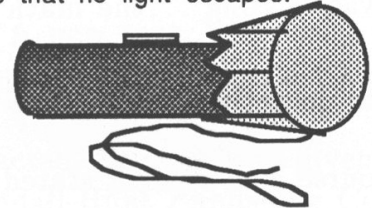

Fig. 8. An experiment to estimate the distances to some bright stars using an "artificial star."

\section{Evaluation}

\section{A. Formative: trial schools}

Feedback from teachers and from students has been essential to the improvement of our curriculum materials. Local astronomy teachers met one Saturday each month during the school year to discuss the units and activities that they tried in the classroom. At these meetings, they shared new ideas for presenting the materials as well as the difficulties encountered by their students.

The national teachers kept records of how the presentations went with their students. The journals contained comments on how the students reacted to the activities, suggestions on improvements to the activities, and the time it took to complete an activity. The following are quotes from the teachers journals:

"Project STAR does what it was intended to do, i.e, to provide average to above-average 11 th and 12 th grade students with meaningful astronomy lab activities."

"...students, as a whole, enjoyed the STAR program..."

"What is being done in these chapters is better than the usual textbook..."

"... my reaction ... is a positive one. Student response ... was also very encouraging."

The most popular activities were:

1. building scale models of the Solar System;

2. building the Celestial Spheres and using them to explain the seasons; and

3. using the Inverse-Square Law to determine the distances to the stars. 
The least popular were:

1. passing around an Earth globe to demonstrate the seasons;

2. using the North Star to determine latitude on Earth; and

3. classifying astronomical objects

Some of the comments from teachers concerning desired improvements were:

"...text was missing ...the math will need to be reduced or explained more simply."

"...hard to do activities all of the time."

And of course, one student stated:

"...I wasn't interested in knowing about how astronomers have found out things."

\section{B. Summative: pre-tests and post-tests}

Both before and after a class had worked through Project STAR materials, the students were tested on their general astronomy knowledge. The pre-test and posttests are the same. This method allows us to represent our effectiveness statistically.

The data for the pre-tests and post-tests are still being collected. Those received so far suggest a slight increase in the scores from before to after. However, the statistical analysis of those data will not be straightforward. For example, there are questions about the validity of the control groups. A more complete analysis of these data will have to wait for the extension of the project.

\section{Dissemination}

\section{A. Conferences}

Members of the STAR staff, Science Panel, and individual consulting teachers have presented 45 papers and workshops. We estimate that a minimum of 3,000 teachers have participated in these various workshops and paper presentations.

\section{B. Newsletter}

STARnews, the project newsletter, keeps us in touch with our constituency. Each of the four issues was distributed to approximately 2500 people, including astronomy teachers on the STAR mailing list and to 300 employees of the Center for Astrophysics. The newsletters included:

- articles by staff and scientists of the CfA

- news of Project STAR current projects

- an "Activity of the Month" for teachers and students 
- profiles of the staff and others involved with Project STAR

- classified ads which solicited help from others

\section{Publishers}

Wide adoption and use of the materials we develop will depend to a large extent on our ability to publish and market a successful and popular new textbook. We are exploring the opportunities for a collaborative effort with an appropriate publisher of national standing. Project STAR has contacted the major publishers of science textbooks in the United States. A new text, backed by the marketing expertise of a knowledgeable publisher, would help to achieve widespread use of these new materials.

In all, two dozen publishers were contacted. Several have given positive reactions. Negotiations are continuing with Kendall-Hunt Publishing Co. of Dubuque, Iowa, and the Smithsonian Press in Washington, D.C.

\section{References}

${ }^{1}$ Welch, Wayne W., Linda J. Harris, Ronald E. Anderson, "How Many are Enrolled in Science?" The Science Teacher, National Science Teachers Association, December 1984.

2"What are the Needs in Pre-college Science?" National Science Foundation, 1979, p. 90 .

${ }^{3} \mathrm{McDermott}$, Lillian C., "Research on conceptual understanding in mechanics," Physics Today, July 1984.

${ }^{4}$ Private conversation with Jack Wilson, executive director of the American Association of Physics Teachers, July 1986.

${ }^{5}$ Welch, W. W., et al., op. cit.

\section{Discussion}

B.W. Jones: Have any follow-up studies been done on the students' understanding, by comparing those who have been through STAR with a control group that has not? Such a follow-up should be done well after completion of the course. It would be alarming to find that the STAR program had little long term impact on understanding.

P. Sadler: Follow-up studies have only been made just after course completion: the STAR group performed significantly better. It would be difficult to do a longer-term follow-up, because the classes are dispersed.

G. Verschuur: A general measure of angle that is useful for everyone is that a fist held out at arm's length subtends an angle of $10^{\circ}$. This fact is useful since the sun moves $15^{\circ}$ per hour, that is, one and a half fists' width, a useful way to figure the 
amount of daylight before sunset. It may be worthwhile using both a fist's width and a $2^{\circ}$ finger's width (for smaller angles) to allow students to estimate angles.

Comment by J. Percy: I have found that, even with university non-science students, angular measure is one of the most difficult concepts for students to understand.

\section{R.J. Dukes, Jr.:}

1. Until all college astronomy students have been exposed to your materials in high school, these materials are useful at the college level.

2. We need to work on astronomy (and all science instruction) at the elementary level. Elementary students are fascinated by science. Between 4 th and 8th grades, we (teachers) kill this interest. This is directly responsible for the decrease in astronomy enrollment after 10th grade. We need projects similar to STAR for elementary schools.

G. Vicino: I agree with all the ideas on which Project STAR is based, and I invite all the Project STAR crew to know the work we are doing in Uruguay. We have a fullyear course of astronomy in our high schools (for pupils 15 or 16 years old) and our program is one of active learning, with a course full of experiments and observations to teach the pupils to think, not to get the knowledge given by a teacher and received in passive form.

N. Sperling: Project STARs sense of proportion seems stuck at the astronomy of 100 years ago - all positional. Most astronomy these days reveals the physical nature of objects, which my students find much more interesting than their locations. Surely modern science principles can be revealed in a superior manner by examples drawn from modern science! Confine the positional astronomy to exercises already developed, and develop physical models next. Try differentiation (a grand unifying principle of planetology). Try stellar evolution from protostellar nebulae to protostellar nebulae. Try nucleosynthesis. Or, for instrumentation, try the tradeoffs in telescope design (see my article "Of Pupils and Brightness," Griffith Observer, January 1985). Try variable stars - apply to classrooms the participatory planetarium program from Lawrence Hall of Science, University of California, Berkeley. Try atmospheric evolution (of the Earth, probably).

D. Hoff: In response to Mr. Sperling's remarks, your concern for inclusion of more modern topics is desirable. Project STAR is concerned with modern topics. We do not propose a modern course. We propose to teach $S$ cience $T$ hrough its $A$ stronomical Roots. That is our name. As a result, our material will not be a fact-laden course. We believe that less may be more.

W. Luzader: Research indicates that most students are not learning positional astronomy by using the "exercises already developed." Phases and seasons should be a part of an introductory astronomy course because people do have strange (if not incorrect) models of how these work and they are natural phenomena that can be easily observed. Any activity that encourages students to look at the real sky and 
follow real events in nature should be used in an introductory course.

How can students "understand" differentiation if they do not know the sequence of planets from closest to farthest from the sun or how that is important to any model of solar system formation? In addressing the concept of nucleosynthesis, is it more important that the student "understand" the difference between fusion and fission and how that relates to the power plant down the road or "learn" the proton-proton or carbon-nitrogen cycles?

Some of the topics mentioned by Mr. Sperling will be addressed in later activities. It should be kept in mind that the existing activities comprise about a fourth to a third of the total materials that will eventually be developed by Project STAR for a full year, high school level, introductory astronomy course. Topics will be chosen and activities written in a way such that their everyday applications can be presented and that certain basic scientific concepts be understood.

R.R. Robbins: The training of teachers to use the materials is especially critical. $I$ recall the death of excellent materials written by Stanley Wyatt and others at the University of Illinois, because the teachers didn't know how to use them.

By the way, I do not agree with the idea that the Wyatt materials were not appropriately designed. They did many of the same things.

W. Bisard: An interesting extension of interviewing students about misconceptions is to interview teachers in general. My experience with "teaching teachers" says we must help them and future generations of teachers.

B. Riddle: We heard a general discussion about modeling and other activities to prepare students at high school level. Comments made concerning need for lessons at elementary school level were also voiced.

Project STARWALK (see poster display) is a program that involves elementary school teachers and their students in lessons centered around three seasonal visits to a planetarium facility. Lessons are designed as classroom activities to prepare students for planetarium visits, and as followup exercises to reinforce and consolidate planetarium lessons. The visit to the planetarium is designed as a laboratory exercise based on concepts dealing with seasons and time. Seasonal stars and constellations are also studied during each visit.

G.A. Carlson: Many textbooks I have used stress that the Earth-moon system is a "double" planet system, and that the moon's orbit is always concave to the sun, never convex. Should I, in an introductory service course, be presenting this concept? From your brief presentation, I got the impression that the concept of "the moon goes around the Earth" is the way to go. How much of the Earth-moon concept do you feel we should present, realizing that 20 per cent of my class are future elementary/secondary teachers?

S.R. Prabhakaran Nayar: Most of the students have the misconception that the waxing and waning of the moon and eclipses are both due to shadowing by by the Earth. It would be worthwhile to discuss both simultaneously and to discuss the 
differences between them.

W. Luzader: Future teachers should "understand" the basics so they can "teach" the basics. I feel that it is more important for a student to understand the phases of the moon and how they relate to eclipses than understanding the orbit of the moon with respect to the sun. The convexity of the moon's orbit would be a good way to test or apply the students' understanding about the Earth-moon-sun system.

N. Pasachoff: In addition to this admirable attempt to restructure astronomy courses, it is also very useful to work within the system. J. Pasachoff and I teamed up some years ago with one of the largest of the Amercian publishers of books for elementary schools and high schools: Scott, Foresman and Co. (Glenview, Illinois). We have provided them with new, expanded, exciting, up-to-date material on astronomy for EARTH SCIENCE (commonly 8th grade, about age 13) and PHYSICAL SCIENCE (commonly 9th grade, about age 14). The first editions of these books, published in 1983, have so far sold over a million copies. Since copies are commonly bought by school systems, and used for a period of at least 5 years, the books are reaching over 5 million students. Thus the opportunity to improve interest in astronomy through normal publishing channels is significant. The second edition is in press (1989 publication), and we have recently contributed astronomy and other material to grades 3 to 6 of Scott, Foresman's elementary school series DISCOVER SCIENCE (1989).

A. Fraknoi: I very much agree with the need for workshops to help teachers do more and better astronomy in the schools. The Astronomical Society of the Pacific has been running 2-day intensive national (and this past year international) workshops for teachers in grades 3 to 12 each summer for the last seven years. We have been especially gratified to see teachers (in elementary and junior-high school) taking these workshops who have absolutely no background in astronomy at all. About 150 to 200 teachers come to take our workshop each year.

Anyone who would like more information on these workshops can feel free to write to the A.S.P. 